\title{
Hospitalisation after birth of infants: cross sectional analysis of potentially avoidable admissions across England using hospital episode statistics
}

\author{
Eleanor Jones ${ }^{1 *}$, Beck Taylor ${ }^{1}$, Gavin Rudge ${ }^{1}$, Christine MacArthur ${ }^{1}$, Deepthi Jyothish², Doug Simkiss ${ }^{3}$ and \\ Carole Cummins ${ }^{1}$
}

\begin{abstract}
Background: Admissions of infants in England have increased substantially but there is little evidence whether this is across the first year or predominately in neonates; and for all or for specific causes. We aimed to characterise this increase, especially those admissions that may be avoidable in the context of postnatal care provision.

Methods: A cross sectional analysis of 1,387,677 infants up to age one admitted to English hospitals between April 2008 and April 2014 using Hospital Episode Statistics and live birth denominators for England from Office for National Statistics. Potentially avoidable conditions were defined through a staged process with a panel.

Results: The rate of hospital admission in the first year of life for physiological jaundice, feeding difficulties and gastroenteritis, the three conditions identified as potentially preventable in the context of postnatal care provision, increased by 39\% (39.55 to 55.33 per 1000 live births) relative to an overall increase of 6\% (334.97 to 354.55 per 1000 live births). Over the first year the biggest increase in admissions occurred in the first 0-6 days (RR 1.26, 95\% Cl 1.24 to 1.29 ) and $85 \%$ of the increase (12.36 to 18.23 per 1000 live births) in this period was for the three potentially preventable conditions.

Conclusions: Most of the increase in infant hospital admissions was in the early neonatal period, the great majority being accounted for by three potentially avoidable conditions especially jaundice and feeding difficulties. This may indicate missed opportunities within the postnatal care pathway and given the enormous NHS cost and parental distress from hospital admission of infants, requires urgent attention.
\end{abstract}

Keywords: Infant admission, Avoidable readmission, Postnatal care

\section{Background}

Hospital admissions, especially emergency ones place a huge cost on health services $[1,2]$ and there is evidence from studies using Hospital Episode Statistics (HES) data for England that emergency admissions of children have increased substantially. In children under 15 between 1999 and 2010 in England all emergency admissions increased with the greatest increase in infants: in 2010 over a third of infants had an admission some time in their first year [3].

\footnotetext{
* Correspondence: exj480@student.bham.ac.uk

${ }^{1}$ Institute of Applied Health Research, University of Birmingham, Edgbaston, Birmingham B15 2TH, England

Full list of author information is available at the end of the article
}

While emergency admissions between 2006 and 2016 increased in all age categories 0-24, this was greatest in those under one [4]. Short-stay ( $<2$ days) unplanned admissions among children up to age 10 increased between 1996 to 2006, again with the greatest increase in children less than one [4]. A study of infant admission in England using HES data showed that between 2005 and 2014, 5.2\% of infants were readmitted unexpectedly within 30 days of postnatal discharge and that the risk of readmission increased by $4.4 \%$ annually from $4.4 \%$ in 2005 to $6.3 \%$ in 2014 [5]. Whilst similar trends have been observed in Scotland [6] in the United States and Canada the proportion of hospital

(c) The Author(s). 2018 Open Access This article is distributed under the terms of the Creative Commons Attribution 4.0 International License (http://creativecommons.org/licenses/by/4.0/), which permits unrestricted use, distribution, and reproduction in any medium, provided you give appropriate credit to the original author(s) and the source, provide a link to the Creative Commons license, and indicate if changes were made. The Creative Commons Public Domain Dedication waiver (http://creativecommons.org/publicdomain/zero/1.0/) applies to the data made available in this article, unless otherwise stated. 
stays for children has decreased or remained relatively unchanged over the period 2000-2012 [5, 7].

Over the last 30 years, the postnatal length of stay in hospital in the UK has reduced considerably: in 198990 , only $44 \%$ women were discharged within two days of giving birth compared to $81 \%$ women in 2016-17 [8]. Over the last decade, the number of women going home on the same calendar day that they gave birth has increased considerably from (16.5\% in $2005 / 06$ to $19.8 \%$ in $2016 / 17$ [8]. Following discharge from hospital, women and babies also have fewer visits from community midwifery services before being discharged to the care of the community health visitor and GP $[9,10]$.

We wanted to know whether the changes to postnatal care provision coincided with the increase in infant admissions which in some cases may have been potentially avoided. We sought to investigate whether the increase in infant admissions was predominantly in the early neonatal period and whether it was confined to a sub-group of conditions more sensitive to the quantity and quality of postnatal care, and therefore amenable to intervention earlier in the care pathway. If findings showed this to be the case, the current five year national maternity review programme in England [11] would provide an opportunity to consider the potential for intervention.

\section{Methods}

Data on all admissions to hospital in the first year of life across England from 1st April 2008 to 31st March 2014 from Hospital Episode Statistics (HES) were included. We developed clinical definitions of potentially avoidable conditions. Admission rates were calculated with denominator data on all live births from Office for National Statistics (ONS). Main outcomes were admissions to hospitals for potentially preventable conditions across different ages within the first year and overall admissions.

An anonymised extract of inpatient data from Hospital Episode Statistics (HES) for all NHS hospitals in England from 1st April 2008 to 31st March 2014 was obtained. HES collects routine demographic data, administrative information and clinical information based on World Health Organisation (WHO) ICD 10 (2008, 2010 and 2014 versions) and OPCS4 and is suitable for research purposes [12]. All admissions (planned and unplanned) of infants less than one year old at the start of their admission episode were extracted. Since the vast majority of infant admissions are unplanned, that is, emergencies, it was decided to include all admissions in these analyses. An inpatient admission was defined as a 'continuous inpatient spell' which is the continuous time spent in hospital from admission to discharge regardless of any within-hospital transfers [12]. This may have included several 'episodes of care' under different medical teams at various NHS care providers. Clinical diagnosis data were obtained from the final discharge episode of the spell. This method was chosen because using the diagnosis from the admission episode might underestimate the case-mix severity in multi-episode spells. The majority of inpatient spells only have one episode which is both the admission and discharge episode. Duplicate cases and cases with an implausible admission/ discharge date were removed and readmissions were explored using the HES identification variable.

To avoid capturing routine admissions to the postnatal ward which frequently occur with a hospital birth, based on the HES data dictionary [12] cases with method of admission codes of '31 (admitted antenatally)', '32 (admitted postnatally), i.e. immediately following delivery, '82 (the birth of a baby in this healthcare provider)'; or ' 83 (baby born outside the healthcare provider except when born at home as intended)' were excluded. Also excluded were cases with episode type given as 'Birth episode'; diagnosis ICD10 coded as 'Z37-Z38' (Singleton, born in Hospital) or admission source coded as '79' (Babies born in or on the way to hospital) (Additional file 1).

The data recorded in HES for each admission included a code for infant age category on admission. Codes for gender, region of admission and ethnicity were also included and a score for social deprivation was assigned, allowing exploration of rate variations by these characteristics. Ethnicity within HES is self-reported and the 16 Census ethnic groups [13] were merged into 5 groups to avoid risk of de-anonymisation for any very small groups when merged with the ONS data: White (British, Irish, Any other white background), Asian (Indian, Pakistani, Bangladeshi, Any other Asian Background), Black (Caribbean, African, Any other black background), Other (White and Black Caribbean, White and Black African, White and Asian, Any other mixed Background, Chinese, Any other ethnic group), Not stated (not stated, missing/null).

Each infant admitted was assigned a Local Authority District and Government Office Region (GOR) of residence based on their lower super output area (LSOA) of residence. A LSOA is a small unit of United Kingdom census geography [14] and contains a mean resident population of approximately 1600 individuals [14]. An index of multiple deprivation 2010 score was assigned to each individual based on the LSOA [15]. The index of multiple deprivation (IMD) is an area based score that combines housing, social and economic indicators to indicate the level of deprivation in each area. The income domain score is the one that most accurately reflects material deprivation as it is based on the Government definition of poverty. These were converted into quintiles by subdividing the ranks of the 32,480 areas in England, quintile 1 being most deprived and quintile 5 least deprived.

Denominator data on all live births across England was provided by Office for National Statistics (ONS), providing 
frequencies of live births by financial year of birth, Region (mothers' area of usual residence), gender, ethnicity (White, Black, Asian, Other, Not stated) and IMD quintile.

Pre-specified definitions of ICD-10 codes of potentially avoidable admissions were produced before analysis of admission rates. The definition of potentially avoidable in this context was a condition or illness which could have been identified before postnatal discharge from hospital or in the community and adequately treated during birth hospitalisation or through community care services. The process for identifying conditions/illness that could be considered potentially avoidable within the HES dataset was undertaken with an advisory panel comprising a consultant general paediatrician, a consultant community paediatrician/professor of child health and a clinical coding manager at a specialist children's hospital. The selection of conditions/illnesses and corresponding coding framework was developed in a four stage approach (Fig. 1). Firstly, frequencies of common illnesses/conditions with the relevant ICD-10 codes by age on admission were produced from the dataset and the paediatricians considered the clinical care pathways, in addition to the physiological and aetiological factors associated with the conditions. Secondly, the list of potentially avoidable conditions and corresponding coding framework was refined. Thirdly, discussion with an expert clinical paediatric coder identified specific HES diagnosis coding rules and standards relevant to the dataset. Finally, a formal list of conditions and corresponding
ICD-10 codes was agreed (Additional file 2). Conditions identified as potentially avoidable were physiological jaundice, feeding difficulties and gastroenteritis and these were pre-specified as the main outcomes prior to data analysis. Potentially avoidable implies that although the infant may require admission to hospital at the point of contact with secondary care services, the risk of developing the illness or the severity of the illness may have been reduced had the problem been identified and an intervention taken place earlier.

Patient involvement was via the National Institute for Health Research Collaboration for Leadership in Applied Health Research and Care West Midlands Patient and Public Involvement Supervisory Committee.

\section{Analyses}

SPSS (V.22) was used to analyse all infant admissions. Summary statistics were used to describe the proportion of avoidable infant admissions in 0-6 days and 7-28 days, 1 to under 3 months, 3 to under 6 months, 6 to under 9 months and 9 to 12 months after birth by condition/illness, ethnicity, deprivation indices, region in England and year of admission. Frequency of admissions by hospital trust was also explored in addition to exploring readmission rates. Unadjusted annual infant admission rates and annual rates for specific conditions and 95\% confidence intervals were calculated by $(\mathrm{N}$ admissions for each year $\mathrm{N}$ live births 2008-09) $\times$ 100. Change in admission rates were
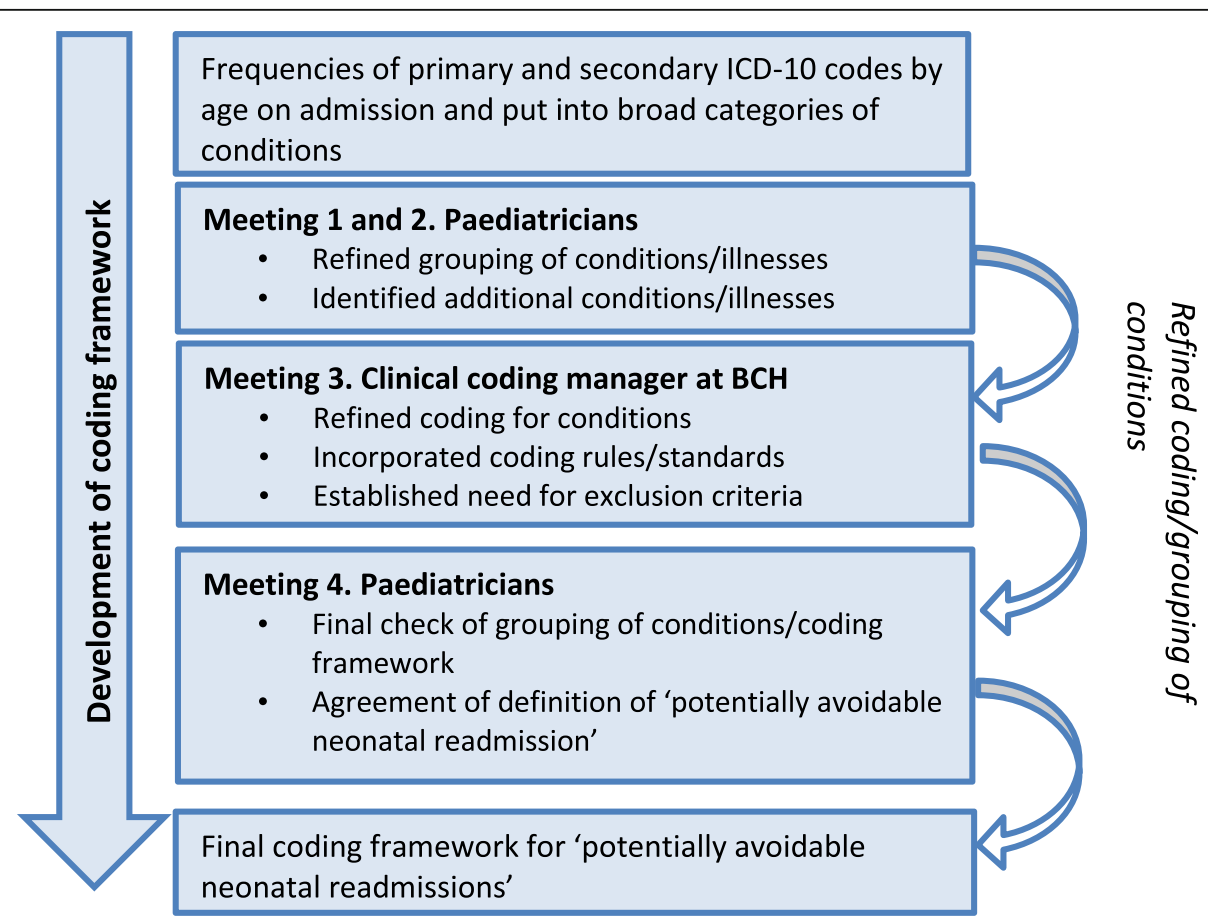

Fig. 1 Process for identifying potentially avoidable admissions and development of the coding framework 
calculated as follows: (rate in 2013-14/rate in 2008-09) $\times$ 100. Where appropriate, Cochrane Armitage tests for trend were conducted to assess significance of the year on year trend over the 6 year period. A sample size calculation was not necessary due to the exploratory and descriptive nature of the study. The following sensitivity analyses were conducted: comparison of the rates of admissions by episodes of care versus spells of care and selecting the primary diagnosis code versus all diagnostic codes.

\section{Results}

There were 1,387,677 admissions in the first year of life and 4,063,050 live births from 1st April 2008 to 31st March 2014. The overall rate of admission increased significantly over the period from 335.0 (95\% CI 333.8$336.1)$ to $354.6(95 \%$ CI 353.6-355.9) per 1000 live births (Table 1). Infants born in 2013/14 had 1.06 times the risk of being admitted to hospital within the first year of life compared to infants born in 2008/09 (Relative risk 1.06, 95\% CI 1.05-1.06). Infants who had one admission were $47 \%$ more likely to be readmitted at least once more within the first year of life. The increase in admissions was most marked for the 0-6 day age category where admission rate increased from 26.39 per 1000 live births (95\% CI 26.01-26.78) in 2008/09 to 33.31 per 1000 live births in $2013 / 14(95 \%$ CI $32.88-33.74)(P<0.0001)$. Infants born in 2013/14 had 1.26 times the risk of being admitted within the first 6 days of life compared with infants born in 2008/09 (Relative risk 1.26, 95\% CI 1.24-1.29) (Fig. 2).

Admission rates also varied considerably by ethnicity where the highest rate of admission was in the 'not stated' ethnicity category (528.22 per 1000 live births (95\% CI 525.93-530.52) compared to 216.85 per 1000 live births (95\% CI 215.11-218.60) in the Black ethnicity category.

The rate of admission for the potentially avoidable conditions increased by $39 \%$ from 39.79 to 55.33 per 1000 live births (Table 2). In the 0-6 day age category the increase in admissions to hospital for these three conditions from 12.36 to 18.23 per 1000 live births contributed $85 \%$ of the increase in admission rate. The rate of admission for infants under 7 days increased by 6.92 per 1000 live births (RR 1.26, 95\% CI 1.24-1.29) however, once the potentially avoidable admissions were removed the rate only increased by 1.05 per 1000 live births (RR 1.07 95\% CI 1.04-1.10) (Table 2).

For physiological jaundice there were a total of 73,403 admissions over the study period, the rate of admission increasing from 16.30 (95\% CI 16.00-16.61) to 22.35 (95\% CI 21.99-22.70) admissions per 1000 live births $(P<0.0001)$ (Table 3$)$. The admission rate in $2013 / 14$ was 1.37 times the risk of being admitted in 2008/09 (RR 1.37 95\% CI 1.34-1.40), an absolute risk increase of 6 per 1000 live births. The increase was concentrated in the $0-6$ day category where the admission rate rose from
8.40 to 12.45 per 1000 with statistically significant increases confined to the first 28 days. (Table 3 ) The duration of hospital admission for physiological jaundice was short with a median length of stay of 1.6 days. The vast majority of infants (94\%) admitted for physiological jaundice had a hospital duration of $\leq 3$ days.

The admission rate for physiological jaundice differed significantly by gender: 44,153 male infants (21.20 per 1000 live births (95\% CI 21.03-21.37) were admitted over the period compared to 29,251 female infants (14.77 per 1000 live births (95\% CI 14.63-14.92). The infant admission rate for physiological jaundice varied by IMD quintile (Table 4), the lowest in the most deprived quintile (16.97 per 1000 live births, 95\% CI 16.7317.21)). The rate of admission for physiological jaundice differed by ethnicity (Table 4). The lowest rate was for black infants where the rate was 6.97 per 1000 live births (95\% CI 6.62-7.33) and the rate of admission was four times higher for infants with an ethnicity code 'not stated' (26.14 per 1000 live births, 95\% CI 25.41-26.87).

The admission rate for feeding difficulties rose from 11.35 (95\% CI 11.10-11.60) per 1000 live births in 2008/ 09 to $13.12(12.85-13.40)$ in $2013 / 14(P<0.0001)$. The age specific admission rate for feeding difficulties varied considerably over the period. The largest increase in risk of admission over the period was in the 0-6 day age category where there was a $46 \%$ increase in $2013 / 14$ compared with 2008/09 (RR 1.46, 95\% CI 1.39-1.54) $(P<0.0001)$. Admissions to hospital for feeding difficulties after one month of age were much less common and the rate consistently decreased with age up to one year (Table 3). The median length of admission for feeding difficulties was 1 day and the majority of infants (91.7\%) had an admission of 3 days or under.

There was no significant difference in the rate of admission by gender: the rate for male infants was 12.57 per 1000 live births (95\% CI 12.42-12.72) compared to 12.37 per 1000 live births (95\% CI 12.22-12.53) for females. There was a small but significant difference in the admission rate for feeding difficulties by IMD quintile with the lowest rate in the most deprived quintile 11.31 per 1000 live births, (95\% CI 11.11-11.50). The lowest rate of admission was observed for black infants (6.59 per 1000 live births, 95\% CI 6.26-6.94) compared to 16.69 in the 'not stated' ethnicity category (95\% CI 16·10-17.28).

For gastroenteritis the rate of infant admission per 1000 live births rose from 12.14 in 2008/09 (95\% CI $11 \cdot 88-12 \cdot 40)$ to $19.86(95 \%$ CI $19.52-20 \cdot 19)(P<0.0001)$. The rate of admission for gastroenteritis significantly increased across all age categories but admission was least frequent in infants in the first 28 days. It was greatest in the 9-12 month age category, although infants aged 1-3 months had the largest relative increase in risk of admission (RR 2.04, 95\% CI 1.90-2.19) from 2008/09-2013/14 


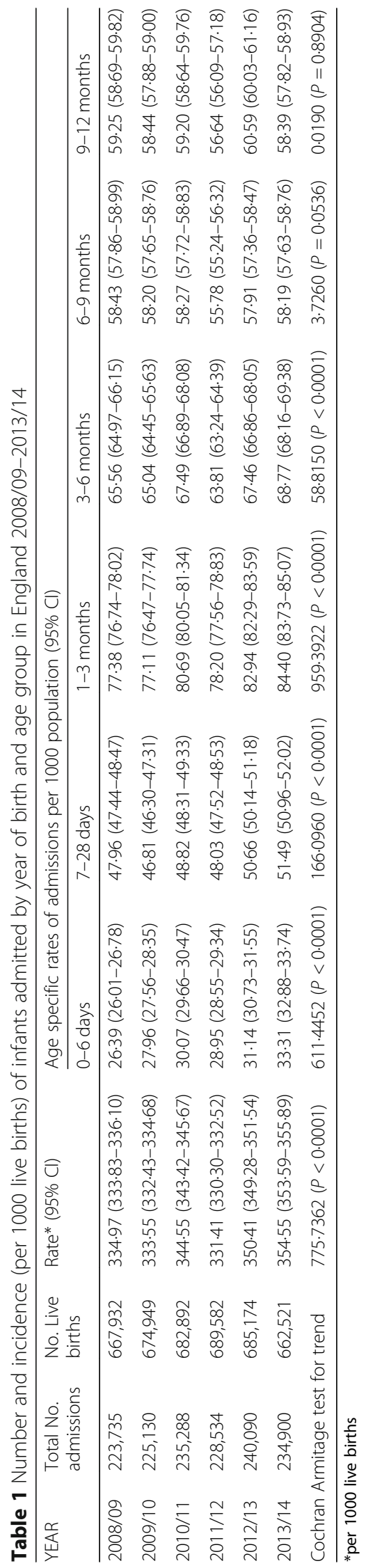




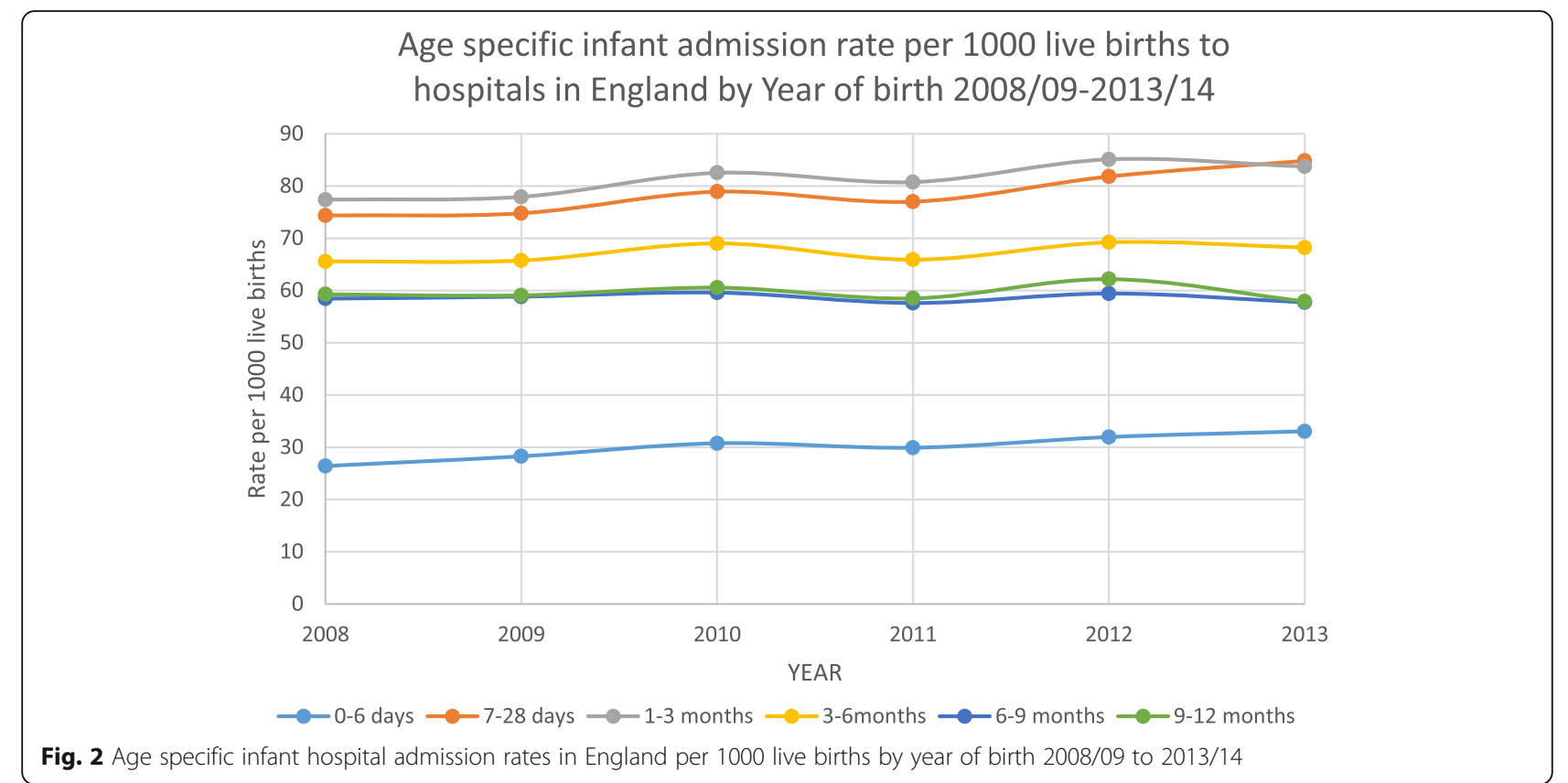

(Table 3). The median length of stay was less than one day and $96.8 \%$ infants were discharged within 3 days.

There was a small but significant difference in rate of admission for gastroenteritis by gender; the rate for male infants was 15.73 per 1000 live births (95\% CI 15.56$15.90)$ and 14.07 (95\% CI 13.90-14.23) for female infants. The highest rate was noted in the most deprived IMD quintile (17.01 per 1000 live births, 95\% CI 16.7717.25) (Table 4). There was also considerable variation by ethnicity, where the rate of admission per 1000 live births was more than double for infants with 'not stated' ethnicity, 18.04 per 1000 live births, (95\% CI 17.4318.65) compared to 8.31 per 1000 live births (95\% CI 7.92-8.69).

The number of admissions for the conditions identified as potentially avoidable varied considerably with high numbers of admissions to bigger paediatric hospitals.

\section{Discussion}

The rate of hospital admission in the first year of life for the three conditions identified as potentially preventable increased by $39 \%$ relative to an overall increase of $6 \%$. Over the first year the biggest increase in admissions occurred in the first $0-6$ days and $85 \%$ of the increase in this period was for the identified potentially preventable conditions of jaundice, feeding difficulties and gastroenteritis for which admissions rose from 12.36 to 18.23 per 1000 live births.

This study used a large routinely collected national dataset and a robust method to develop a working definition of 'potentially avoidable' infant admissions in the context of postnatal care provision, drawing on the expertise of paediatricians, research data analysts and clinical coders. The potentially avoidable conditions were pre-specified prior to calculation of admission rates. The

Table 2 Frequency and rate (per 1000 live births) of admission for infants aged 0-6 days (overall and potentially preventable conditions (physiological jaundice, feeding difficulties and gastroenteritis))

\begin{tabular}{llllll}
\hline YEAR & overall No. admissions & No. avoidable conditions & No. live births & rate overall admission $^{\text {admission rate for }} \begin{array}{c}\text { fotentially avoidable } \\
\text { conditions }\end{array}$ \\
\hline $2008 / 09$ & 17,629 & 8257 & 667,932 & $26 \cdot 39$ & $12 \cdot 36$ \\
$2009 / 10$ & 18,869 & 8798 & 674,949 & 27.96 & $13 \cdot 04$ \\
$2010 / 11$ & 20,534 & 9932 & 682,892 & 30.07 & $14 \cdot 54$ \\
$2011 / 12$ & 19,962 & 10,313 & 689,582 & 28.95 & $14 \cdot 96$ \\
$2012 / 13$ & 21,334 & 11,373 & 685,174 & $31 \cdot 14$ & $16 \cdot 60$ \\
$2013 / 14$ & 22,067 & 12,079 & 662,521 & $33 \cdot 31$ & $18 \cdot 23$ \\
\hline
\end{tabular}




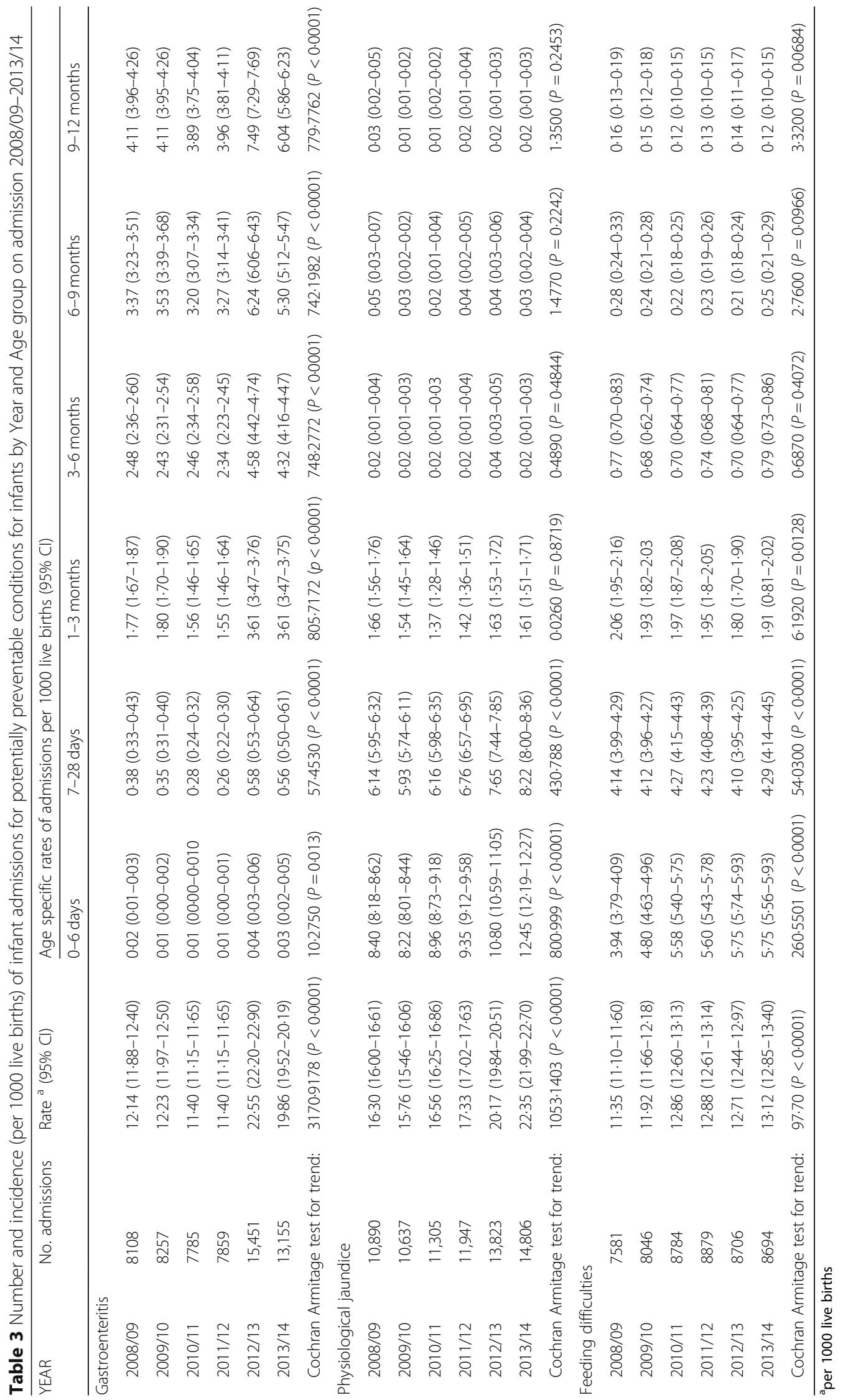


Table 4 Number and incidence (per 1000 live births) of infant admissions for potentially preventable conditions by Ethnicity, Gender, and IMD quintile 2008/09-2013/14

\begin{tabular}{|c|c|c|c|c|c|c|}
\hline & \multicolumn{2}{|c|}{ Feeding difficulties } & \multicolumn{2}{|l|}{ Gastroenteritis } & \multicolumn{2}{|c|}{ Physiological Jaundice } \\
\hline & No admissions & Rate $(95 \% \mathrm{Cl})$ & No admissions & Rate $(95 \% \mathrm{Cl})$ & No admissions & Rate $(95 \%$ Cl) \\
\hline \multicolumn{7}{|l|}{ Ethnicity $^{a}$} \\
\hline White & 37,746 & $12 \cdot 81(12 \cdot 68-12 \cdot 94)$ & 47,616 & $16 \cdot 16(16 \cdot 01-16 \cdot 30)$ & 51,082 & $17.34(17.19-17.48)$ \\
\hline Asian & 5102 & $12 \cdot 19(11 \cdot 86-12.52)$ & 4570 & $10 \cdot 92(10 \cdot 60-11 \cdot 23)$ & 9517 & $22 \cdot 74(22 \cdot 28-23 \cdot 19)$ \\
\hline Black & 1415 & $6.59(6.25-6.94)$ & 1783 & $8.31(7.92-8.69)$ & 1497 & $6.97(6.62-7.33)$ \\
\hline Other & 3391 & $11.26(10.89-11.64)$ & 3365 & $11 \cdot 18(10 \cdot 80-11.55)$ & 6556 & $21 \cdot 78(21 \cdot 26-22 \cdot 30)$ \\
\hline Not stated & 3036 & $16 \cdot 69(16 \cdot 10-17 \cdot 28)$ & 3282 & $18.04(17.43-18.65)$ & 4756 & $26 \cdot 14(25 \cdot 41-26 \cdot 87)$ \\
\hline \multicolumn{7}{|l|}{ Gender } \\
\hline Male & 26,183 & $12 \cdot 57(12 \cdot 42-12 \cdot 72)$ & 32,761 & $15.73(15 \cdot 56-15.90)$ & 44,153 & $21.20(21.03-21.37)$ \\
\hline Female & 24,502 & $12 \cdot 37(12 \cdot 22-12.53)$ & 27,854 & $14.07(13.90-14.23)$ & 29,251 & $14.77(14.63-14.92)$ \\
\hline \multicolumn{7}{|l|}{ IMD Index ${ }^{a}$} \\
\hline 1 & 12,708 & $11 \cdot 31(11 \cdot 11-11 \cdot 50)$ & 19,122 & $17.01(16 \cdot 77-17 \cdot 25)$ & 19,077 & $16.97(16.73-17.21)$ \\
\hline 2 & 10,860 & $11 \cdot 89(11 \cdot 67-12 \cdot 11)$ & 13,967 & $15 \cdot 29(15 \cdot 04-15 \cdot 55)$ & 16,111 & $17.64(17.37-17.91)$ \\
\hline 3 & 9899 & $13 \cdot 14(12 \cdot 82-13 \cdot 40)$ & 10,903 & $14 \cdot 47(14 \cdot 20-14 \cdot 74)$ & 14,084 & 18.69 (18.39-19.00) \\
\hline 4 & 8952 & $13.63(13.35-13.91)$ & 8953 & $13.63(13.35-13.91)$ & 12,367 & $18.83(18.50-19.16)$ \\
\hline 5 & 7995 & $12 \cdot 99(12 \cdot 71-13 \cdot 27)$ & 7254 & $11.78(11.51-12.05)$ & 11,245 & $18.27(17.93-18.60)$ \\
\hline
\end{tabular}

${ }^{a}$ Missing data:

Gastroenteritis: $0.7 \%$ IMD index, $0.6 \%$ Ethnicity

Physiological Jaundice: 0.9\% IMD index, $0.6 \%$ Ethnicity

Feeding difficulties: $0.8 \%$ IMD index, $0.4 \%$ ethnicity

coding framework used to identify such admissions incorporated inclusion and exclusion criteria to ensure that infants with underlying conditions were excluded from the sample population (for example, infants born with cleft lip and palate, and subsequent feeding difficulties). It is reassuring that the incidence of admissions for physiological jaundice and feeding difficulties over the age of 3 months was very small, suggesting that the selection of codes for these conditions was accurate. Although a systematic review of coding accuracy studies suggested that HES data has improved significantly over time [16], it is unlikely that this would have affected our study findings because the NHS Payment by Results system, a key driver for improving HES data accuracy, had been fully implemented by $2007[17,18]$.

HES is widely accepted as a database for health research and suitable for studies identifying trends in healthcare [19], although there are a number of limitations. The ethnicity variable was not as complete as other data fields with $7 \%$ of infant admissions having a 'missing' or 'not known' code. Previous research has indicated that missing ethnicity data may not be random and instead relates to service pressures, a lack of opportunity for health professionals enquiry or the circumstances of hospital admission $[20,21]$. Additionally, the broad denominator ethnicity categories necessary to maintain confidentiality prohibited a thorough assessment of admission rates by ethnicity. It was not possible to explore hospital level admission rates because denominator data were not available at hospital level but we anticipate that variation would be affected by patient and hospital level factors. Finally, we did not have data on smoking status and breastfeeding status.

Use of age specific admission rates for infants under one year showed that the increase in admission over the period 2008 to 2014 only existed within the first 6 months of life, and had increased most in the 0-6 day category. The admission rate for infants from 6 to 12 months remained stable over the period. Our findings are consistent with those of other studies that explore unplanned infant admissions to hospital [6]. It is also consistent with the literature in the finding that the rate of admissions varied by IMD [22]. The overall admission rate to hospital by IMD quintiles supports existing evidence that admission rates are strongly correlated with measures of social deprivation [22]. For admission rates for jaundice and feeding difficulties however the admission rate was highest in the least deprived quintiles and may reflect variation in infant feeding practices with women in the least deprived quintiles more likely to breastfeed. Inability to initiate and establish breastfeeding resulting in an insufficient milk supply is a known risk factor for physiological jaundice [23]. Exclusive initial breastfeeding initially rose from $65 \%$ in 2005 to $69 \%$ in 2010 when $46 \%$ of babies were still 
exclusively breastfed at one week [24]. While breastfeeding may be a factor influencing the trends seen, it does not provide a sufficient explanation of them. Increases in admission rates for gastroenteritis showed a different pattern from jaundice and feeding difficulties as the increase for this was greatest in infants after the first month and may possibly be related to feeding practices and insufficient support for infant feeding.

The change in infant admission rates we observed over the period was concentrated in those under 7 days of age and for the potentially avoidable conditions, particularly jaundice and feeding difficulties. In England over a similar period of time women and infants have had less routine contact with health professionals as the length of stay in hospital after birth and the median community visits following discharge from birth has reduced $[9,10]$. Over the period of this study, the average postnatal length of stay hospital reduced slightly from 1.7 days in $2008 / 09$ to 1.5 days in $2013 / 14$ [25]). Several large surveys of women's experiences of postnatal care have shown that a large proportion felt that they needed more support, particularly establishing breastfeeding [11, 26-29]. Although temporal association does not prove causation, the increase in admissions may in part prove to be attributed to changes in the postnatal care provision and management of neonates in the community. Other possible causes to the increase observed in this study include an increase in parents being advised by NHS 111 system to take their child straight to hospital, and a decrease in training and experience for doctors to triage neonates in primary care [3]. If the reduction in postnatal care provision does have a part to play in the increase in infant admission rate, the current National Maternity Review in England [11] aimed at transforming maternity services has the opportunity to ensure that women's needs are being met prior to discharge from hospital. It could also ensure that women are able to have more effective community provision including more frequent home visits where needed and easy access to midwifery advice in order to identify potential infant health problems to improve this situation.

\section{Conclusion}

Our findings show that most of the increase in the rate of admission to hospital for infants up to age one over the period 2008-2014 was in the early neonatal period; and the great majority of this increase is explained by the three conditions, physiological jaundice, feeding difficulties and gastroenteritis, predominantly the former two. Potential missed opportunities within the postnatal care pathway require urgent modification given current NHS capacity and resource issues.

\section{Additional files}

Additional file 1: Flow chart of the process for identifying infant admissions under the age of 1 year unrelated to birth admissions in Hospital Episode Statistics. (DOCX $43 \mathrm{~kb}$ )

Additional file 2: Coding framework for potentially avoidable infant admissions. (DOCX $17 \mathrm{~kb}$ )

\section{Abbreviations}

GOR: Local Authority District and Government Office Region; HES: Hospital Episode Statistics; IMD: Index of multiple deprivation; LSOA: Lower super output area; ONS: Office for National Statistics; WHO: World Health Organisation

\section{Acknowledgements}

With thanks to Paul Allen at Birmingham Children's Hospital NHS Trust for his contribution to the design of the coding framework for potentially avoidable conditions.

\section{Funding}

This paper presents independent research funded by the National Institute for Health Research (NIHR) Collaboration for Leadership in Applied Health Research and Care West Midlands. The views expressed are those of the author(s) and not necessarily those of the NHS, the NIHR or the Department of Health. Carole Cummins, Christine Macarthur and Beck Taylor report funding and Eleanor Jones a stipend from NIHR CLARHC West Midlands, during the conduct of the study.

\section{Availability of data and materials}

The data that support the findings of this study are available from the $\mathrm{HSCIC}$ but restrictions apply to the availability of these data, which are used under license for the current study, and so are not publically available. Data provided by ONS are available at: https://www.ons.gov.uk/.

\section{Authors' contributions}

EJ, CC, CM and BT conceived the study. GR extracted the data. EJ, CC, CM, BT, DS and DJ developed the definition of potentially avoidable infant admission and ICD 10 and OPCS 4 coding framework. EJ, CC, CM and BT were responsible for statistical analysis and interpretation. All authors contributed to the manuscript draft and critical revision of the manuscript for intellectual content. All authors read and approved the final manuscript.

\section{Ethics approval and consent to participate}

An application to HSCIC to hold a national extract of admitted patient care data was approved by the Data Access Advisory Group at the Health and Social Care Information Centre. A self-assessment form was submitted to University of Birmingham Ethics Committee indicating that access to the data had been granted.

\section{Consent for publication}

N/A

\section{Competing interests}

The authors declare that they have no competing interests.

\section{Publisher's Note}

Springer Nature remains neutral with regard to jurisdictional claims in published maps and institutional affiliations.

\section{Author details}

${ }^{1}$ Institute of Applied Health Research, University of Birmingham, Edgbaston, Birmingham B15 2TH, England. 'Birmingham Women's and Children's NHS Foundation Trust, Steelhouse Lane, Birmingham B4 6NH, England. ${ }^{3}$ Division of Mental Health and Wellbeing, Warwick Medical School, University of Warwick, Coventry, UK. 
Received: 9 February 2018 Accepted: 30 November 2018

Published online: 20 December 2018

\section{References}

1. Blunt I. Focus on preventable admissions. Trends in emergency admission for ambulatory care sensitive conditions 2001-2013. http://www. qualitywatch.org.uk/sites/files/qualitywatch/field/field_document/131010_ QualityWatch_Focus_Preventable_Admissions.pdf. Accessed 8 June 2017.

2. Purdy S. Avoiding hospital admission. What does the research say? The King's Fund. 2010. http://www.kingsfund.org.uk/sites/files/kf/AvoidingHospital-Admissions-Sarah-Purdy-December2010.pdf. Accessed 8 June 2017.

3. Gill P, Goldacre M, Mant D. Increase in emergency admissions to hospital for children aged under 15 in England, 1999-2010: national database analysis. Arch Dis Child. 2013;98:328-34.

4. Saxena S, Bottle A, Gilbert R, Sharland M. Increasing short-stay unplanned hospital admissions among children in England; time trends analysis '97-'06. PLoS One. 2009:4:10

5. Harron K, Gilbert R, Cromwell D, Oddie S, Meulen J. Newborn length of stay and risk of readmission. Paediatr Perinat Epidemiol. 2017;31:221-32.

6. Al-Mahtot M, Barwise-Munro R, Wilson P, Turner S. Changing characteristics of hospital admissions but not the children admitted - a whole population study between 2000 and 2013. Eur J Pediatr. 2018;177:381-8.

7. Witt W, Weiss A, Elixhauser A. Overview of Hospital Stays for Children in the United States, 2012. HCUP statistical brief \#187. Rockville, MD: Agency for Healthcare Research and Quality; 2014. https://www.hcup-us.ahrq.gov/.

8. NHS Digital. NHS maternity statistics 2016-17. 2017 https://digital.nhs.uk/ data-and-information/publications/statistical/nhs-maternity-statistics. Accessed 10 Oct 2018

9. Byrom S, Edwards G, Bick D. Essential midwifery practice. Postnatal care. 2009. [electronic resource], Chichester Ames, lowa: Wiley-Blackwell.

10. Care Quality Commission. Maternity Survey: Quality and Methodology Report. 2017:2017 https://www.cqc.org.uk/publications/surveys/maternityservices-survey-2017. Accessed 10 June 2018.

11. NHS England. National Maternity Review: better births - improving outcomes of maternity services in England - a five year forward view for maternity care. 2016. https://www.england.nhs.uk/wp-content/uploads/ 2016/02/national-maternity-review-report.pdf. Accessed 8 June 2017.

12. NHS Digital. HES Data Dictionary: Admitted patient Care (APC) Hospital Episode Statistics. 2017. NHS digital. Leeds; http://content.digital.nhs.uk/ media/23711/Admitted-Patient-Care/pdf/Admitted_Patient_Care_.pdf. Accessed 8 June 2017

13. Office for National Statistics. Population estimates by Ethnic Group: methodology Paper: London: 2011. https://www.ons.gov.uk/ peoplepopulationandcommunity/populationandmigration/ populationestimates/methodologies/populationestimatesbyethnicgroup. Accessed 8 June 2017).

14. Office for National Statistics. Census geography. https://www.ons.gov. uk/methodology/geography/ukgeographies/censusgeography. Accessed 8 June 2017).

15. Department for communities and Local Government. The English Indices of deprivation 2010. London; 2011. https://www.gov.uk/government/uploads/ system/uploads/attachment_data/file/6871/1871208.pdf. Accessed 8 June 2017.

16. Burns EM, Rigby E, Mamidanna R, Bottle A, Aylin P, Ziprin P, Faiz OD. Systematic review of discharge coding accuracy. J Public Health. 2012:34:138-48

17. Department of Health. Reforming NHS financial flows - Introducing Payment by Results. 2002, Department of Health, London. http:// webarchive.nationalarchives.gov.uk/20130107105354/http://www.dh.gov. uk/prod_consum_dh/groups/dh_digitalassets/@dh/@en/documents/ digitalasset/dh_4018704.pdf. Accessed 8 June 2017.

18. Confirmation of PbR arrangements for 2007/08, Gateway reference 7539 , 2006, Department of Health https://webarchive.nationalarchives.gov.uk/+/ http://www.dh.gov.uk/en/Publicationsandstatistics/Publications/ PublicationsPolicyAndGuidance/DH_062914. Accessed 8 June 2017.

19. Garrett E, Barnes H, Dibbin C. Health Administrative Data: exploring potential for academic research. St Andrews: Administrative Data Liaison Service. http://www.academia.edu/10325382/Health_administrative_data_ Exploring the potential_for_academic research. Accessed 8 June 2017.

20. Fraser LK, McKinney PA, Parslow RC, Miller M, Aldridge J, Hain R, et al. Rising national prevalence of life-limiting conditions in children in England. Pediatrics. 2012;129:923-e9.
21. Mathur R, Bhaskaran K, Chaturvedi N, Leon DA, vanStaa T, Grundy E, et al. Completeness and usability of ethnicity data in UK-based primary care and hospital databases. J Public Health. 2014;36:684-92.

22. Majeed A, Bardsley M, Morgan D, O'Sullivan C, Bindman AB. Cross sectional study of primary care groups in London: association of measures of socioeconomic and health status with hospital admission rates. BMJ. 2000;321:1057-60.

23. Lain S, Roberts C, Bowen J, Nassar N. Early discharge of infants and risk of readmission for jaundice. Pediatrics. 135:314-21.

24. McAndrew F, Thompson J, Fellow L. Large A. Infant Feeding Survey: Speed M and Renfrew M; 2010. http://content.digital.nhs.uk/catalogue/PUB08694/ Infant-Feeding-Survey-2010-Consolidated-Report.pdf . Accessed 8 June 2017

25. NHS digital. NHS Maternity Statistics in England 2013-2014 [Online]. NHS digital. http://www.hscic.gov.uk/catalogue/PUB16725. Accessed 8 June 2017.

26. Redshaw M, Rowe R, Hockley C, Brocklehurst P. Recorded delivery: a national survey of women's experience of maternity care 2006. Oxford: The National Perinatal Epidemiology Unit; 2007.

27. Redshaw M, Henderson J. Safely delivered: a national survey of women's experience of maternity care 2014. Oxford: The National Perinatal Epidemiology Unit; 2015.

28. Bhavnani $V$, Newburn M. Left to your own devices: the postnatal care experiences of 1260 first time mothers. London: National Childbirth Trust; 2010.

29. Care Quality Commission. National findings from the. Survey of women's experiences of maternity care. London: Care Quality Commission; 2013. p. 2013.

\section{Ready to submit your research? Choose BMC and benefit from:}

- fast, convenient online submission

- thorough peer review by experienced researchers in your field

- rapid publication on acceptance

- support for research data, including large and complex data types

- gold Open Access which fosters wider collaboration and increased citations

- maximum visibility for your research: over $100 \mathrm{M}$ website views per year

At $\mathrm{BMC}$, research is always in progress.

Learn more biomedcentral.com/submissions 